\title{
Therapeutic Potential of Calendula officinalis
}

\begin{abstract}
Calendula officinalis (Calendula), belonging to the family of Asteraceae, commonly known as English Marigold or Pot Marigold is an aromatic herb which is used in Traditional system of medicine for treating wounds, ulcers, herpes, scars, skin damage, frost-bite and blood purification. It is mainly used because of its various biological activities to treat diseases as analgesic, anti-diabetic, anti-ulcer and anti-inflammatory. It is also used for gastro-intestinal diseases, gynecological problems, eye diseases, skin injuries and some cases of burn. Calendula oil is still medicinally used as, an anti-tumor agent, and a remedy for healing wounds. Plant pharmacological studies have suggested that Calendula extracts have antiviral and anti-genotoxic properties in-vitro. In herbalism, Calendula in suspension or in tincture is used topically for treating acne, reducing inflammation, controlling bleeding, and soothing irritated tissue. Calendula is used for protection against the plague. In early American Shaker medicine, calendula was a treatment for gangrene. In addition to its first aid uses, calendula also acts as a digestive remedy. An infusion or tincture of the flowers, taken internally, is beneficial in the treatment of yeast infections, and diarrhea. An infusion of Calendula officinalis may also be used to treat bee stings, eye inflammations, boils and abscesses, varicose veins, eczema, and as a gargle for mouth sores or to relieve toothache. It improves the circulation of the blood $\&$ the lymphatic fluids and aids in elimination of toxins from the body. This plant is rich in many pharmaceutical active ingredients like carotenoids, flavonoids, glycosides, steroids and sterols quinines, volatile oil, and amino acids. The extract of this plant as well as pure compound isolated from it, has been demonstrated to possess multiple pharmacological activities such as anti-cytotoxic, hepato-protective and spasmolytic amongst others. Acute toxicity studies in rats and mice suggest that the extract is relatively nontoxic. Animal tests have demonstrated minimal skin irritation, and no sensitization or photo toxicity. Minimal ocular irritation was seen with one formulation and no irritation with others. Six saponins isolated from C. officinalis flowers were not mutagenic in an Ames test, and a tea derived from $C$. officinalis was not genotoxic in Drosophila melanogaster. Clinical testing of cosmetic formulations containing the extract elicited little irritation or sensitization. This review has explored the organoleptic, in-vitro and in-vivo pharmacological activities as well as description, cultivation and active chemical constituents of Calendula officinalis in order to existing information on this plant as well as highlighted its multi activity properties as a medicinal agent.
\end{abstract}

Keywords: Calendula officinalis, anti-ulcer, antiviral, anti-genotoxic, anti-inflammatory, hepato-protective, spasmolytic properties
Volume 6 Issue 2 - 2018

\author{
Vrish Dhwaj Ashwlayan, Amrish Kumar, \\ Mansi Verma,Vipin Kumar Garg, SK Gupta \\ Department of Pharmaceutical Technology, Meerut Institute of \\ Engineering and Technology, India
}

Correspondence: Vrish Dhwaj Ashwlayan, Department of Pharmaceutical Technology, Meerut Institute of Engineering and Technology, India, Email vrish.ashwlayan@miet.ac.in

Received: January 20, 2018 | Published: April 20, 2018

\section{Introduction}

Calendula officinalis belonging to the family Asteraceae is a well known medicinal plant. It is commonly known as English marigold, pot marigold. Chemically, Calendula officinalis possesses various biological active constituents such as carotenoids, flavonoids, saponins, sterols, phenolic acids, lipids, etc. Various parts of plant such as leaves, flowers have been reported to possess therapeutic activity. ${ }^{1}$ The flowers were made into extracts, tinctures, balms and salves and applied directly to the skin to help heal wounds and to soothe inflamed and damaged skin. Advanced analytical techniques have been used to isolate novel chemical constituents such as isorhamnetin, rutin, quercetin glucoside, which are biologically active as well as used in food and cosmetic industry. ${ }^{2}$ The plant has yellow or orange coloured flowers which are used as food, dye, spice, tea, ointment or cream in cosmetics. It possesses cytotoxic as well as tumor reducing potential. Traditionally, Calendula officinalis was used as anti-inflammatory, diaphoretic, analgesic, antiseptic and in jaundice treatment. ${ }^{3}$ However, it is pointed out that flowers of the plant have been reported to be most potent therapeutically. The pleiotropic properties of this meritocratic plant include anti-ulcer, anti HIV, immune-stimulant, wound healing. ${ }^{4}$ internally, it is used for mucous membrane inflammations, peptic and duodenal ulcers, spasms of the GI tract, duodenal and intestinal mucosa, dysmenorrhea (painful menstruation) especially in nervous or anemic women, splenic and hepatic inflammations. Generally in cases of external use, it is clinically given for treating skin inflammations, open wounds and laceration wounds with bleeding. It is also used for treating minor diseases like razor burns and wind burns. It is also used as a mouthwash after tooth extractions. ${ }^{5}$

\section{Uses of calendula}

Sedative drugs: In early animal studies, high doses of ingested calendula preparations were reported to act as sedatives. Therefore, combination use with sedative agents may lead to additive effects. In rats, calendula was shown to increase hexobarbital induced sleeping time. A systemic effect after topical use of calendula in human is not clear.

Antihypertensive drugs: In early animal studies, high doses of calendula preparations were reported to possess hypertensive effects. Therefore, combination use with hypertensive agents may lead to additive effects. 
Hypoglycemic drugs: Calendula may increase the activity of hypoglycemic medications or insulin.

Cholesterol-lowering drugs: Calendula may have an additive effect with agents that decrease lipids and triglycerides.

\section{Classification of Calendula officinalis6-9}

Kingdom-Plantae

Subkingdom-Tracheobionta

Division-Magnoliophyta

Class-Magnoliopsida

Subclass-Asteridae

Order-Asterales

Family-Asteraceae

Tribe-Calenduleae

Genus-Calendula

Species-officinalis

\section{Synonyms}

Pot marigold, English marigold, Bride of the Sun, bull flower, butterwort

\section{Description}

Calendula officinalis is a short-lived aromatic herbaceous perennial, growing to $80 \mathrm{~cm}(31 \mathrm{in})$ tall, with sparsely branched lax or erect stems. The leaves are oblong-lance. The disc florets are tubular and hermaphrodite, and generally of a more intense orange olate, $5-17 \mathrm{~cm}$ (2-7in) long, hairy on both sides, and with margins entire or occasionally waved or weakly toothed. The inflorescences are yellow, comprising a thick capitulum or flower head 4-7cm diameter surrounded by two rows of hairy bracts; in the wild plant they have a single ring of ray florets surrounding the central disc florets-yellow colour than the female, tridentate, peripheral ray florets. The flowers may appear all year long where conditions are suitable. The fruit is a thorny curved achene. ${ }^{10}$

\section{Organoleptic properties}

The odour of Calendula officinalis is faint and aromatic.

The taste of Calendula officinalis is bitter.

\section{Cultivation}

The plant is native to Central and Southern Europe, Western Asia and the US. ${ }^{11}$ Calendula officinalis is widely cultivated and can be grown easily in sunny locations in most kinds of soils. Although perennial, it is commonly treated as an annual, particularly in colder regions where its winter survival is poor and in hot summer locations where it also does not survive. Calendulas are considered by many gardening experts as among the easiest and most versatile flowers to grow in a garden, especially because they tolerate most soils. In temperate climates, seeds are sown in spring for blooms that last throughout the summer and well into the fall. In areas of limited winter freezing, seeds are sown in autumn for winter color. Plants will wither in subtropical summer. Seeds will germinate freely in sunny or halfsunny locations, but plants do best if planted in sunny locations with rich, well-drained soil. Pot marigolds typically bloom quickly from seed (in under two months) in bright yellows, golds, and oranges.

\section{Discussion}

\section{Phytochemistry of Calendula officinalis}

A number of phytochemical studies have well reported about the presence of several classes of chemical compounds, the main ones being terpenoids, flavonoids, coumarin, quinines, volatile oil, carotenoids and amino acids in the plant.

Terpenoids: Various terpenoids have been reported from the petroleum ether extract of $C$. officinalis flowers. They include sitosterols, stigmasterols, ${ }^{12}$ diesters of diols, ${ }^{13} 3$-monoesters of taraxasterol, lupeol, ${ }^{14,15}$ erythrodiol, brein, ${ }^{16,17}$ ursadiol, ${ }^{18}$ faradiol3-O-palmitate, faradiol-3-Omyristate, faradiol-3-O-laurate, ${ }^{19}$ arnidiol-3-O-palmitate, arnidiol-3-O-myristate, arnidiol-3-O-laurate, calenduladiol-3-Opalmitate, $\quad$ calenduladiol-3-O-myristate, ${ }^{20,21}$ oleanolic acid saponins: calenduloside $\mathrm{AH},{ }^{22-23}$ oleanane triterpene glycoside: calendula glycoside A, calendulaglycosideA6-O-nmethylester, calendulaglycoside $\mathrm{A} 66^{\circ e}-\mathrm{O}-\mathrm{n}$-butylester, calendula glycoside B, calendulaglycosideB6-O-n-butylester, calendula glycoside $\mathrm{C}$, calendula glycoside $\mathrm{C}$ 6-O-n-methyl ester, calendula glycoside C 6- O-n-butyl ester, calenduloside F6-O-n-butyl ester, calenduloside G6-O-n-methyl ester, glucoside of oleanolic acid (mainly found in roots of grown and senescing plants) I, II, III, VI, $\mathrm{VII},{ }^{24,25}$ and glucuronides (mainly found in flowers and green parts) $\mathrm{F}$, $\mathrm{D}, \mathrm{D} 2, \mathrm{C}, \mathrm{B}$ and $\mathrm{A} .{ }^{26}$ One new triterpenic ester of oleanane series has been isolated from flowers was cornulacic acid acetate from flowers. ${ }^{27}$

Flavonoids: Various flavonoids have been isolated from the ethanol extract of the inflorescence of $C$. officinalis. They include quercetin, isorhamnetin, ${ }^{28}$ isoquercetin, isorhamnetin-3-O-D-glycoside, narcissin, calendoflaside, ${ }^{29}$ calendoflavoside, calendoflavobioside, rutin, isoquercetin neohesperidoside, isorhamnetin-3Oneohesperidoside, isorhamnetin-3-O-2G- rhamnosyl rutinoside, isorhamnetin-3-Orutinoside, quercetin-3-O-glucoside and quercetin3-O-rutinoside. ${ }^{30}$

Coumarins: The ethanol extract of the inflorescence of the C. officinalis was reported to contain coumarins-scopoletin, umbelliferone and esculetin. ${ }^{31}$

Quinones: Quinones reported from C. officinalis were plastoquinone, phylloquinone, and tocopherol in the chloroplast, ubiquinone, phylloquinone, tocopherol in mitochondria, and

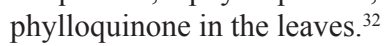

Volatile oil: $C$. officinalis flowers contain maximum volatile oil at full flowering stage $(0.97 \%)$ and minimum during the pre-flowering stage $(0.13 \%)$. The composition also showed different patterns at different phases of vegetative cycles. Various monoterpenes and sesquiterpenes have been reported in the volatile oil : $\alpha$-thujene, $\alpha$-pienene, sabinene, $\beta$-pienene, limonene, 1,8-cineol, p-cymene, trans- $\beta$-ocimene, $\Upsilon$-terpenene, $\delta$-3-carene, nonanal, terpene-4-ol, 3 -cylohexene-1-ol, $\alpha$-phellandrene, $\alpha$-terpeneol, geraniol, carvacrol, bornyl acetate, sabinyl acetate, $\alpha$-cubebene, $\alpha$-copaene, $\alpha$-bourbonene, cubebene, $\alpha$-gurjunene, aromadendrene, $\beta$-aryophyllene, $\alpha$-ylangene, $\alpha$-humulene, epibicyclosequiphellandrene, germacrene $\mathrm{D}$, allo aromadendrene, $\beta$-saliene, calarene, muurolene, $\delta$-cadinene, cadina 1,4-diene, $\alpha$-cadinene, nerolidol, palustron, endobourbonene, oplopenone, $\alpha$-cadinol, Tmuurolol. The essential oil was found to be 
rich in $\alpha$-cadinene, $\alpha$-cadinol, $t$-muurolol, limonene, and 1,8-cineol with p-cymene at lower levels at the post-flowering periods. ${ }^{33}$

Carotenoids: The methanol extract of leaves, petals and pollens of C. officinalis flowers showed a number of carotenoids. The carotenoids found in the pollens and petals were neoxanthin, 9Z-neoxanthin, violaxanthin, luteoxanthin, auroxanthin,9Z-violaxanthin, flavoxanthin, mutatoxanthin, 9Zanthroxanthin, lutein, 9/9"A-lutein, 13/13" Zlutein, $\alpha$-cryptoxanthin, $\beta$-cryptoxanthin, $\quad \mathrm{z}$-cryptoxanthin, lycopene, $\alpha$-carotene, and $\beta$-carotene. Total carotenoid ( $\mathrm{mg} / \mathrm{g}$ dry weight) was $7.71 \%$ for petals and $1.61 \%$ for pollens. Carotenoid compositions of the leaves and stems were reported as neoxanthin, 9Zneoxanthin, violaxanthin, luteoxanthin, 9Zviolaxanthin, 13Z-violaxanthin, antheraxanthin, mutatoxanthin epimer 1 , mutatoxanthin epimer 2 , lutein, 9/9"2-lutein, $\alpha$-cryptoxanthin, $\beta$-cryptoxanthin, $\beta$-carotene. Total carotenoids ( $\mathrm{mg} / \mathrm{g}$ dry weight) for the leaves is $0.85 \%$ and for stems $0.18 \% .^{34,35}$ Glycosides of quercetin and isorhamnetin were the predominant components of the flavonoids, while beta-carotene and lutein were the most abundant carotenoids. ${ }^{36}$ Analysis of carotenoid composition in petals of Calendula officinalis was made. Nineteen carotenoids were identified in extracts of petals of orange and yellow flowered cultivars of calendula.

In addition, ten carotenoids were unique to orange-flowered cultivars. The ultraviolet (UV) visible absorption maxima of these ten carotenoids were at longer wavelengths than that of flavoxanthin, the main carotenoid of calendula petals providing the evidence that these carotenoids are responsible for the orange color of the petals. Six carotenoids had a cis structure at $\mathrm{C}-5\left(\mathrm{C}-5^{\prime}\right)$ and it is conceivable that these (5Z)-carotenoids are enzymatically isomerised at $\mathrm{C}-5$ in a pathway that diverges from the main carotenoid biosynthesis pathway. Among them, (5Z, 9Z)-lycopene, (5Z, 9Z, 5'Z, 9'Z)-lycopene, (5'Z)gamma-carotene, (5'Z, 9'Z)- rubixanthin and (5Z, 9Z, 5'Z)-lycopene have been identified. ${ }^{37}$ According to the Research work on specificity of the tonoplast, transport of oleanolic acid monoglycosides in the vacuoles from Calendula officinalis leaves, the proper structure of both parts of oleanolic acid monoglycoside, i.e. aglycon and the sugar moiety, are required for binding to a specific tonoplast carrier. ${ }^{38}$ These two glycosides were isolated from leaf protoplasts of the plant with the use of chemically synthesized analogues. Structures of new ionone and sesquiterpene glycosides were investigated from Egyptian Calendula officinalis. Two new ionone glucosides (officinosides A and B) and two sesquiterpene oligoglycosides (officinosides C and D) were isolated from the flowers of Egyptian Calendula officinalis, the structures of which were elucidated on the basis of chemical and physicochemical evidences. ${ }^{39}$

Amino acids: The ethanol extract of the flowers of the plant is reported to show the presence of 15 amino acids in free form: Alanine, arginine, aspartic acid, asparagines, valine, histidine, glutamic acid, leucine, lysine, proline, serine, tyrosine, threonine, methionine and phenylalanine. Amino acid content of the leaves is about $5 \%$, stems $3.5 \%$ and flowers $4.5 \%{ }^{40}$

Carbohydrates: The ethanol extract of the inflorescence of plant showed the presence of polysaccharides, PS-I,-II, and III having a (1-3)-D-galactam backbone with short side chains at C-6 comprising -araban(1-3)-araban and alpha-L-rhamnan-(1-3)- araban along with monosaccharide's. ${ }^{41,42}$

Lipids: The lipids in the petroleum ether extract of the seeds, leaves and flowers of $C$. officinalis have been analyzed. The amount of neutral lipids in the seeds was $15.7 \%$, phospholipids $0.6 \%$ and glycolipids $0.9 \%$. Fatty acids of monols, sterol esters, 3-monoesters, 3-monoester diols reported in flowers were lauric, myristic, palmitic, stearic, oleic, linoleic and linolenic acid. The fatty acids of marigold seeds contain about $59 \%$ of an $18: 3$ conjugated trienic (trans- 8 , trans- 10 , cis- 12 ) acid and about $5 \%$ of 9-hydroxy-18:2 (trans-9,cis-11) acid-dimorphecolic acid $^{43,44}$ one oxygenated fatty acid also reported from the seed oil of $C$. officinalis was D-(+)-9-hydroxy-10,12-octadecadienoic acid. ${ }^{45}$

Other constituents: Other phytochemicals include the bitter constituent, loliolide (calendin), ${ }^{46}$ calendulin $^{47}$ and paraffins. ${ }^{48}$

\section{Therapeutic potential}

\section{In-vivo pharmacology activities of calendula officinalis}

Antidiabetic and anti hyperlipidemic activities: Diabetes was induced to the rat by single intraperitoneal injection of alloxan $(150 \mathrm{mg} / \mathrm{kg})$ of body weight. The blood glucose level and urine sugar level were significantly elevated in diabetic rats compared to normal rats. Upon oral administration of hydro alcoholic extract of Calendula officinalis in diabetic rats at dose 25 and $50 \mathrm{mg} / \mathrm{kg}$ body weight significantly lowered the blood glucose and urine sugar as they compared with group of diabetics rats. Hydro alcoholic extract of Calendula officinalis in diabetic rats at a dose of $100 \mathrm{mg} /$ $\mathrm{kg}$ body weight was found to be highly significant as it restored all the parameters to the normal levels of blood glucose, urine sugar and serum lipid in alloxan diabetic rats. The extract increases the total hemoglobin level. The extract was similar to that of insulin. Thus, the investigation clearly shows that hydro alcoholic extract of Calendula officinalis has both antidiabetic and antihyperlipidemic effects. ${ }^{49}$ The structures of the officinosides were elucidated on the basis of chemical and physicochemical evidence. The inhibitory activities of the principal saponins from the flowers of $C$. officinalis was noted on the increase of serum glucose levels in oral glucose-loaded rats, on gastric emptying in carboxy methyl cellulose sodium salt test mealloaded mice, and on ethanol or indomethacin induced gastric mucosal lesions in rats and also discussed the structure requirements for this activities..$^{50}$

Cardiovascular activities: Calendula officinalis could be cardioprotective against ischemic heart disease .Two groups of hearts were used: the treated rat hearts were perfused with Calendula officinalis solution at $50 \mathrm{mM}$ in KHB buffer (in $\mathrm{mM}$ ) sodium chloride $118 \mathrm{mM}$, potassium chloride $4.7 \mathrm{mM}$, calcium chloride $1.7 \mathrm{mM}$, sodium bicarbonate $25 \mathrm{mM}$, potassium biphosphate $0.36 \mathrm{mM}$, magnesium sulfate $1.2 \mathrm{mM}$, and glucose $10 \mathrm{mM}$ ) for $15 \mathrm{~min}$ prior to subjecting the heart to ischemia, while the control group was perfused with the buffer only. Calendula achieved cardio protection by stimulating left ventricular developed pressure and aortic flow as well as by reducing myocardial infarct size and cardiomyocytes apoptosis. Cardio protection appears to be achieved by changing ischemia reperfusionmediated death signal into a survival signal by modulating antioxidant and anti-inflammatory pathways as evidenced by the activation of Akt and Bcl 2 and depression of TNF $\alpha$. The results further strengthen the concept of using natural products in degeneration diseases like ischemic heart disease. ${ }^{51}$

Hepatoprotective activities: The $80 \%$ methanolic extract of Calendula officinalis leaves was investigated against acetaminopheninduced hepatic damage in 30 male albino rats. Acetaminophen produces $100 \%$ mortality at dose of $1 \mathrm{gm} / \mathrm{kg}$ in mice, while 
pretreatment of mice with Calendula officinalis $(1.0 \mathrm{gm} / \mathrm{kg})$ reduced the death to $30 \%$. Pretreatment of mice with leaves extract $(500 \mathrm{mg} /$ $\mathrm{kg}$ orally, four doses at 12 hours interval) prevented $(\mathrm{p}<0.05)$ the acetaminophen $(640 \mathrm{mg} / \mathrm{kg}$ induced rise in serum transaminases (SGOT, SGPT), serum bilirubin and serum alkaline phosphatase. Post treatment with three successive doses of leaves extract $(500 \mathrm{mg} / \mathrm{kg}$. 6 hourly)) restricted the hepatic damage induced by acetaminophen $(\mathrm{p}<0.05) .^{52}$

Antioxidant effects: An extract of Calendula officinalis Linn., was evaluated for its antioxidant potential by oral administration of Calendula alcoholic extract inhibit superoxide generation in macrophages in female swiss albino mice by $12.6 \%$ and $38.7 \%$ at doses of 100 and $250 \mathrm{mg} / \mathrm{kg}$ body wt. Oral administration of Calendula officinalis to mice for 1 month significantly increased catalase activity. The extract produced significant increase in glutathione levels in blood and liver. Glutathione reductase was found to be increased, whereas glutathione peroxidase was found to be decreased after administration of Calendula extract. ${ }^{53}$

Anthelmintic activities: The dried flowers and leaves of $C$. officinalis have anthelmintic activity. The aqueous extract of dried flowers and leaves of $C$. officinalis were prepared by decoction method. The assay was performed on Indian adult earth worm, due to its anatomical and physiological resemblance with the intestinal round worm parasite of human being. Calendula officinalis flowers and leaf extracts were also shown to have anthelmintic activity the crude extracts of $C$. officinalis flowers and leaf extracts demonstrated paralysis at $56.5 \mathrm{~min}$ and death of worms at 111.2 minutes. The plants contain saponins and have also shown anthelmintic potential which are in accordance with previous reports which reveals that saponins are known to have anthelmintic activity. ${ }^{54}$

Anti-inflammatory activities: The ethanolic extract of Calendula officinalis possessed significant anti-inflammatory activity against carrageenan and dextran-induced paw edema. Oral administration of the 250 and $500 \mathrm{mg} / \mathrm{kg}$ body weight of Calendula officinalis extract produced significant inhibition (50.6 and $65.9 \%$ respectively) in paw edema of animal induced by carrageenan and 42.9 and $42.4 \%$ respectively with inflammation produced by dextran. In chronic anti-inflammatory model using formalin, administration of 250 and $500 \mathrm{mg} / \mathrm{kg}$ body weight calendula extract produced an inhibition of 32.9 and $62.3 \%$ respectively compared to controls. TNF- $\alpha$ production by macrophage culture treated with lipopolysaccharide (LPS) was found to be significantly inhibited by extract. Moreover, increased levels of proinflammatory cytokines IL- $1 \beta$, IL-6, TNF- $\alpha$ and IFN- $\gamma$ and acute phase protein, $\mathrm{C}$ reactive protein (CRP) in mice produced by LPS injection were inhibited significantly by the extract. LPS induced cyclooxygenase-2 (Cox-2) level in mice spleen were also found to be inhibited by extract treatment. The results showed that potent anti-inflammatory response of $C$. officinalis extract may be mediated by the inhibition of pro-innflammatory cytokines and CoX2 and subsequent prostaglandin synthesis. ${ }^{24}$ Topical application of a $70 \%$ ethanol extract of the flowers to mice at a dose of $1.2 \mathrm{mg} /$ ear (corresponding to $4.16 \mathrm{mg}$ crude drug) reduced croton oil-induced ear oedema by $20 \%$. External application of a carbon dioxide extract of the flowers $\left(300 \mathrm{mg} / \mathrm{cm}^{2}\right)$ suppressed croton oil induced ear oedema in mice. ${ }^{55}$

Wound-healing and angiogenic activities: Angiogenic activity of Calendula officinalis L. (Asteraceae) ethanolic extract and dichloromethane and hexanic fractions were evaluated by using Models 36 rats and 90 embryonated eggs to evaluate healing and angiogenic activities of extracts and fractions of the plant, through the induction of skin wounds and the chorioallantoic membrane, respectively. The effect of vascular proliferation was also tested from the study to verify the intensity of expression of vascular endothelial growth factor (VEGF) in cutaneous wounds in rats. In morphometric evaluation increase of the vascular area and of percentage of redmarked areas was observed in CAM treated as positive control $1 \%$ (17 B-estradiol), ethanolic extract 1\%, dichloromethane fraction $1 \%$ and hexanic fraction $1 \%$, compared to solvent control (ethanol $70 \%$ ). Digital planimetry by point counting performed on mice derm trated with ethanolic extract $1 \%$ revealed an increase in the number of blood vessels compared to solvent control. ${ }^{56}$ They reported a statistically significant difference in reduction of total wound area compared with the control $(p<0.05)$, showing an overall decrease of $41.71 \%$ in the experimental group compared with $14.52 \%$ in the control group. They conclude that application of Calendula extract significantly increases epithelization in chronic venous ulcerations. Marigold therapy offers a non-invasive and gentle treatment for difficult to treat plantar verruca, painful hyperkeratotic lesions, and inflamed bursa secondary to hallux abducto valgus. ${ }^{57}$

Anticancer activities: The results obtained indicated that none of the extracts had a direct mitogenic effect on human lymphocytes or thymocytes (stimulation index, $\mathrm{SI}<0.07$ ). Among the plants studied, C. officinalis showed a complete inhibitory effect on the proliferation of lymphocytes in the presence of PHA (SI range 0.01-0.49). ${ }^{58}$

\section{In-vitro pharmacology activities of calendula officinalis}

Hepatoprotective activities: The potential hepatoprotective effects of Calendula officinalis and morus Alba extracts was noted against cytotoxicity and oxidative stress induced by carbon tetrachloride $(\mathrm{CCl} 4)$ in isolated primary rat hepatocytes. The dose response effect of different concentrations of Calendula officinalis and Morus Alba extracts $(1,10,100$ and $1000 \mu \mathrm{g} / \mathrm{ml})$ on CCl4 induced decrease in the viability $\%$ of isolated rat hepatocytes. Hepatocytes were isolated by collagenase perfusion two steps technique. Cytotoxicity was determined by assessing cell viability and leakage of cytosolic enzymes, such as alanine aminotransferase (ALT), aspartate aminotransferase (AST) and lactate dehydrogenase (LDH). Oxidative stress was assessed by determining reduced glutathione (GSH) level and lipid peroxidation as indicated by thiobarbituric acid reactive substances (TBARS) production. Exposure of isolated rat hepatocytes to $\mathrm{CCl}_{4}$ caused cytotoxicity and oxidative injury, manifested by loss of cell viability and significant increase in ALT, AST and LDH leakages. As well as, $\mathrm{CCl}_{4}$ caused progressive depletion of intracellular GSH content and significant enhancement of TBARS accumulation. Pre-incubation of hepatocytes with either Calendula officinalis or morus alba extracts ameliorated the hepatotoxicity and oxidative stress induced by $\mathrm{CCl}_{4}$, as indicated by significant improvement in cell viability and enzymes leakages (ALT, AST and LDH) and also, significant improvement of GSH content and significant decrease in TBARS formation as compared to $\mathrm{CCl}_{4}$ treated cells. The dose response effect of different concentrations of Calendula officinalis and morus alba extracts $(1,10,100$ and $1000 \mu \mathrm{g} / \mathrm{ml})$ on $\mathrm{CCl}_{4}$ induced decrease in the viability $\%$ of isolated rat hepatocytes. The results revealed that $\mathrm{CCl}_{4}(5 \mathrm{mM})$ induced significant decrease in the viability $\%$ of isolated rat hepatocytes after $30 \mathrm{~min}$ of incubation period. This decrease in the viability was a time dependant compared to a control group. ${ }^{59}$ 
Antibacterial activities: Ethanolic and aqueous extracts of Calendula officinalis inhibit the growth of the bacteria used in the study, at concentrations ranging from $125 \mu \mathrm{g} / \mathrm{ml}$ to $64 \mathrm{mg} / \mathrm{ml}$. Methanolic extract inhibited the growth of both S. aureus and E. coli at $64 \mathrm{mg} / \mathrm{ml}$. Aqueous extract of Calendula officinalis exhibited highest antibacterial activity against all the bacteria tested. S. aureus was found to be more susceptible as compared to other bacteria. ${ }^{60}$ The antibacterial activities of Calendula officinalis Linn. Dried leaf powder of Calendula officinalis was successively extracted with petroleum ether, chloroform and ethanol using Soxhlet and macerated to form water extract. All extracts were screened for its antibacterial and antifungal activity using agar well diffusion method. The microorganisms used for antibacterial and antifungal were Bacillus subtulis, Staphylococcus aureus, Escherichia coli, Klebsiella pneumonia, Candida albicans and Aspergillus niger. Gentamicin $5 \mu \mathrm{g} / \mathrm{ml}$ was used as standard. The extracts showed antimicrobial activity were subjected to minimum inhibitory concentration assay by two fold dilutions method. Petroleum ether, chloroform, ethanol and water extract exhibited in-vitro antibacterial activity ${ }^{61}$ Antimicrobial activity of ethanolic, methanolic, acetone and chloroform extract of C. officinalis was studied against the gram-positive besterial strains were Escherichia coli, Staphylococcus anrens, and the gram-negative strains were Salmonella typhae and Vibrio cholera.The fungal strain used was Candida albicans. Ethanolic extract gave activity against E. coli, Vibrio cholera and Candida albicans. Methanolic extract gave only against Candida albicans. Chloroform gave antimicrobial activity against all microbes while acetone gave only against $E$. coli. ${ }^{62}$

Anticancer activities: The flavonoid extracts $(0.05-50 \mu \mathrm{g} / \mathrm{ml}) \mathrm{did}$ not cause significant effect on the proliferation of two cell lines. It may be related to the attached sugar molecule at the position 3 of flavones that can reduce its ability to bind aromatase and other enzymes. ${ }^{63}$ Thirteen saponins were isolated and identified from Calendula officinalis, C. arvensis and Hedera helix. Mutagenic and antimutagenic activities of these products were investigated using a modified liquid incubation technique of the Salmonella/microsomal assay. The Salmonella tester strain $\mathrm{TA} 98 \pm \mathrm{S} 9$ mix was used. Screening of the antimutagenic activity was performed with a known promutagen: benzo-[a] pyrene and mutagenic urine concentrate from a smoker. Antimutagenic activities were also compared with the activity of chlorophyllin. All the saponins were found to be non-toxic and non-mutagenic for dose of $400 \mathrm{ug} / \mathrm{kg} .{ }^{64}$

Anti-inflammatory activities: The hydro alcoholic extract of Calendula officinalis can suppress the activities of 5-lipoxygenase (5LO) and cyclooxygenase-2 (COX-2) (key enzymes) in the formation of pro inflammatory eicosanoids from arachidonic acid. ${ }^{65}$ The occurrence of acute dermatitis of grade 2 or higher was significantly lower $(41 \%$ v $63 \% ; p<.001)$ with the use of calendula than with trolamine. Moreover, patients receiving calendula had less frequent interruption of radiotherapy and significantly reduced radiationinduced pain. Calendula is highly effective for the prevention of acute dermatitis of grade 2 or higher and should be proposed for patients undergoing postoperative irradiation for breast cancer. ${ }^{66}$

Antioxidant activities: Aqueous extract of petals showed higher antioxidant activity than the leaves. The results obtained in the present study indicate that the leaves and petals of Calendula officinalis are a potential source of natural antioxidants ${ }^{67}$ An alcoholic extract of Calendula officinalis Linn (Composite) was evaluated for its antioxidant potential in vitro. Calendula officinalis extract was found to scavenge superoxide radicals generated by photo reduction of riboflavin and hydroxyl radicals generated by Fenton reaction and inhibited in vitro lipid peroxidation. Concentrations needed for $50 \%$ inhibition (IC50) were 500, 480, and $2000 \mathrm{mg} / \mathrm{ml}$, respectively. Extract scavenged ABTS radicals and DPPH radicals and IC50 were 6.5 and $100 \mathrm{mg} / \mathrm{ml}$, respectively ${ }^{68}$ For Calendula officinalis extract of $7.5 \mathrm{mg} /$ $\mathrm{ml}$ concentration, the LPO decreased slowly with dose from $68 \%$ to $40 \%$ at $20 \mathrm{kGy}$. The LPO for $3.75 \mathrm{mg} / \mathrm{ml}$ concentration decreased suddenly from $56 \%$ to $28 \%$ at $1 \mathrm{kGy}$ dose. Then, it decreased slowly with dose. ${ }^{69}$

Anti-HIV activities: Chloroform extract of the flowers inhibited the replication of HIV-1 in acutely infected lymphocytic MOLT-4 cells in vitro (IC50 $0.4 \mathrm{mg} / \mathrm{ml}$ ). A chloroform extract also inhibited HIV-1 reverse transcriptase activity in a dose-dependent manner (ED50 51.0mg/ml). ${ }^{70}$

\section{Conclusion}

The various pharmacological properties have been attributed in preclinical research to various constituents, including antiinflammatory, immune-stimulating, antibacterial, antiviral, antiprotozoal and antineoplastic properties. The juice from the fresh flowers or stem is said to help remove warts and help to heal mucous membranes and skin. An infusion or tincture of the herb is also helpful in cases of painful or delayed menstruation, and the herb is a beneficial ally in the transition to menopause. The tincture also has many other uses, such as a topical wash for diaper rash in infants, a mouth gargle for sores, a vaginal douche for yeast, an internal soother for inflamed lungs, a topical for hemorrhoids. $\mathrm{A} \mathrm{LD}_{50}$ of $375 \mathrm{mg} / \mathrm{kg}$ and a $\mathrm{LD}_{100}$ of $580 \mathrm{mg} / \mathrm{kg}$ has been reported in mice by intravenous and intraperitoneal administration of aqueous extract of Calendula offcinalis. In hydro-alcoholic extracts a $\mathrm{LD}_{50}$ of $45 \mathrm{mg} /$ mouse (subcutaneous) and $\mathrm{LD}_{50}$ of $526 \mathrm{mg} / 100 \mathrm{~g}$ in rats (intravenous) have been reported. Calendula officinalis extract is reported to be used in almost 200 cosmetic formulations, over a wide range of product categories. Two homologous cDNAs, CoFad2 and CoFac2, were isolated from a Calendula officinalis developing seed by a polymerase chain reaction-based cloning strategy. Both sequences share similarity to FAD2 desaturases and FAD2-related enzymes. In C. officinalis plants $\mathrm{CoFad} 2$ was expressed in all tissues tested, whereas $\mathrm{CoFac} 2$ expression was specific to developing seeds. Expression of CoFad2 cDNA in yeast (Saccharomyces cerevisiae) indicated it encodes a Delta12 desaturase that introduces a double bond at the 12 position of 16:1(9Z) and 18:1(9Z). Expression of CoFac2 in yeast revealed that the encoded enzyme acts as a fatty acid conjugate converting 18:2(9Z, $12 \mathrm{Z}$ ) to calendic acid 18:3(8E, 10E, 12Z). The enzyme also has weak activity on the mono-unsaturated 16:1(9Z) and 18:1(9Z) producing compounds with the properties of 8,10 conjugated dienes.

\section{Acknowledgement}

None.

\section{Conflict of interest}

None.

\section{References}

1. Muley BP, Khadabadi SS, Banarase NB. Phytochemical constituents and 
pharmacological activities of Calendula officinalis Linn (Asteraceae) a review. Trop J Pharm Res. 2009;8(5):455-465.

2. Albulescu M, Alexa N, Cojan C. Calendula officinalis flowers, source of extracts with antioxidant activity. Annals of West University of Timisoara: Series Chemistry. 2004;13(2):169-176.

3. Chakraborthy GS. Phytochemical screening of Calendula officinalis Linn leaf extract by TLC. Int J Res Ayurveda Pharm. 2010;1(1):131-134.

4. Arora D, Rani A, Sharma A. Review on phytochemistry and ethnopharmacological aspects of genus Calendula. Pharmacogn Rev. 2013;7(14):179-187.

5. Mukesh S, Pankaj S, Nagori K, et al. Organoleptic properties in-vitro and in-vivo pharmacological activities of Calendula officinalis Linn. J Chem Pharm Res. 2011;3(4):655-663.

6. World Health Organization. Monographs on selected medicinal plants: Flos Calendulae. Switzerland; 2004. 358p.

7. Master data/Monograph-Calendula officinalis (pot marigold). 2007; 5p.

8. Calendula officinalis. Wikipedia; 2009.

9. Parente LM, Andrade MA, Brito LA, et al. Angiogenic activity of Calendula officinalis flowers L. in rats. Acta Cir Bras. 2011;26(1):19-26.

10. Tyler VE. The Therapeutic Use of Phytomedicinals. Herbs of Choice: New York; 1994.

11. PDR for Herbal Medicines. Medical Economics Company: Montvale; 2003. 1106p.

12. Adler G, Kasprzyk Z. Free sterols, steryl esters, glycosides, acelyted glycosides and watersoluble complexes in Calendula officinalis. Phytochem. 1975;14(3):627-631.

13. Wilkomirski B, Kasprzyk Z. Free and ester-bound triterpene alcohols and sterols in cellular subfractions of Calendula officinalis. Phytochem. 1979; 18(2):253-255.

14. Wilkomirski B. Pentacyclic triterpene triols from Calendula officinalis flowers. Phytochem. 1985;24(12):3066-3067.

15. Zittwel-Eglseer K, Sosa S, Jurenitsch J, et al. Anti-oedematous activities of the main triterpenoid esters of marigold (Calendula officinalis L.). $J$ Ethnopharmacol. 1997;57(2):139-144.

16. Wojciechowski Z, Bochenska HM, Kurcharezak B, et al. Sterol and triterpene alcohol esters from Calendula officinalis. Phytochem. 1972;11(3):1165-1168.

17. Kasprzyk Z, Wilkomirski B. Structure of a new triterpene triol from Calendula officinalis flowers. Phytochem. 1973;12(9):2299-2300.

18. Sliwowski J, Dziewanowska K, Kasprzyk Z. (1973) Ursadiol: A new triterpene diol from Calendula officinalis flowers. Phytochem. 1973;12(1):157-160.

19. Eitterl-Eglseer K, Reznicek G, Jurenitsch J, et al. Morphogenetic variability of faradiol monoesters in marigold Calendula officinalis $\mathrm{L}$. Phytochem Anal. 2001;12(3):199-201.

20. Neukiron H, D’Ambrosio M, Dalla J, et al. Simultaneous Quantitative Determination of Eight Triterpenoid Monoesters from Flowers of 10 Varieties of Calendula officinalis L. and Characterisation of a New Triterpenoid Monoester. Phytochem Anal. 2004;15(1):30-35.

21. Ukiya M, Akihisa T, Yasukava K, et al. Anti -inflammatory, antiTumor Promoting and Cytotoxic Activities of Constituents of Marigold (Calendula officinalis) Flowers. J Nat Prod. 2006;69(12):1692-1696.

22. Vecherko LP, Sviridov AF, Zinkevich EP, et al. Structures of calendulosides $\mathrm{G}$ and $\mathrm{H}$ from the roots of Calendula officinalis. Chem Nat Compd. 1974;10(4):548-549.

23. Vecherko LP, Sviridov AF, Zinkevich EP, et al. The structure of calenduloside C and D from the roots of Calendula officinalis. Chem Nat Compd. 1975;11(3):379-384.

24. Ruszkowski D, Szakiel A, Janiszowska W, et al. Metabolism of [3$3 \mathrm{H}]$ oleanolic acid in Calendula officinalis L roots. Acta Physiologiae Plantarum. 2003;25(4):311-317.

25. Wojciechowski Z, Jelonkiewicz KA, Tomaszewski M, et al. The structure of glucosides of oleanolic acid isolated from the roots of Calendula officinalis flowers. Phytochem. 1971;10(5):1121-1124.

26. Vidal-Ollivier E, Balansard G. Revised structures of triterpenoid saponins from the flowers of Calendula officinalis. J Nat Prod. 1989;52(5):11561159.

27. Naved T, Ansari SH, Mukhtar HM et al. New triterpenic esters of oleaneneseries from the flowers of Calendula officinalis Linn. Indian Journal of Chemistry. 44(5):1088-1091.

28. Kurkin VA, Sharova OV. Flavonoids from Calendula officinalis flowers Chem Nat Compd. 2007;43(2):216-217.

29. Vidal-Ollivier E, Elias R, Faure F, et al. Flavonol glycosides from Calendula officinalis flowers. Planta Med. 1989;55(1):73-74.

30. Ukiya M, Akihisa T, Yasukava K, et al. Anti- inflammatory, antiTumor Promoting and Cytotoxic Activities of Constituents of Marigold (Calendula officinalis ) Flowers. J Nat Prod. 2006;69(12):1692-1696.

31. Kerkach AI, Komissarenko NF, Chernobai VT. Coumarines of the inflorescences of Calendula officinalis and Helichrysum arenarium. Chem Nat Compd. 1986;22(6):722-723.

32. Janiszowska W, Michalski W, Kasprzyk Z. Polyprenyl quinones and $\alpha$-tocopherol in Calendula officinalis. Phytochem. 1976;15(1):125-127.

33. Okoh OO, Sadimenko AA, Afolayan AJ. The effects of age on the yield and composition of the essential oils of Calendula officinalis. J Appl Sci. 2007;7(23):3806-3810.

34. Bako E, Deli J, Toth G. HPLC study on the carotenoid composition of Calendula products. J Biochem Biophys Methods. 2002;53(1-3):241-250.

35. Goodwin TW. Studies in carotenogenesis: the carotenoids of the flower petals of Calendula officinalis. Biochem J. 1954;58(1):90-94.

36. Piccaglia R, Marotti M, Avari G, et al. Effects of Harvesting Date and Climate on the Flavonoid and Carotenoid Contents of Calendula officinalis L. Flavour and Fragance Journal. 1997;12(2):85-90.

37. Kishimoto S, Maoka T, Sumitomo K, et.al. Analysis of carotenoid composition in petals of Calendula officinalis L. Biosci Biotechnol Biochem. 2005;69(11):2122-2128.

38. Szakiel A, Janiszowska W. Reversibility of the oleanolic acid monoglycosides transport across the tonoplast in vacuoles isolated from Calendula officinalis leaves. Acta Biochim Pol. 1997;44(1):55-59.

39. Lin LT, Liu LT, Chiang LC et al. In vitro anti-hepatoma activity of fifteen natural medicines from Canada. Phytother Res. 2002;16(5):440-444.

40. Abajova RL, Aslanov SM, Mamedova ME. Amino acids of Calendula officinalis. Chem Nat Compd. 1994;30(5):641.

41. Varlijen J, Andras L, Hildebert W. Structural analysis of rhamnoarabinogalactans and arabinogalactans with immune-stimulating activity from Calendula officinalis. Phytochem. 1989;28(9):2379-2383.

42. Wagner H, Proksch A, Riess-Maurer I et al. Immunostimulating action of polysaccharides (heteroglycans) from higher plants. Arzneimitelforschung. 1985;35(7):1069-1075.

43. Vlchenko NT, Glushenkova AI, Mukhamedova KS. Lipids of Calendula officinalis. Chem Nat Compd. 1998;34(3):272-274.

44. Wilkomirski B, Kasprzyk Z. Free and ester-bound triterpene alcohols and sterols in calendula flowers. Phytochemistry. 1979;18(2):253-255. 
45. Badami RC, Morris LJ. The oxygenated fatty acid of calendula seeds oil J Am Oil Chem Soc. 1965;42:1119-1121.

46. Willuhn G, Westhaus RG. Loliolide (Calendin) from Calendula officinalis Planta Med. 1987;53(3):304.

47. Fleisonner AM. Plant extracts: to accelerate healing and reduce inflammation. Cosmet Toilet. 1985;45:100-113.

48. Komoe H, Hayashi N. n-Paraffins of the petals of Calendula officinalis. Phytochemistry. 1971;10(8):1944.

49. Chakraborthy GS, Arora R, Majee C. Antidiabetic and Antihyperlipidaemic Effect of Hydoalcoholic extract of Calendula officinalis. Int Res J Pharm. 2011;2(1):61-65.

50. Marukami T, Kishi A, Yoshikawa M. Medicinal flowers. IV. Marigold. (2): structures of new ionone and sesquiterpene glycosides from Egyptian Calendula officinalis. Chem Pharm Bull. 2001;49(8):974-978.

51. Ray D, Mukherjee S, Falchi M, et al. Amelioration of myocardial ischemic reperfusion injury with Calendula officinalis. Curr Pharm Biotechnol. 2010;11(8):849-854.

52. Ali J, Khan A. Preventive and Curative Effects of Calendula-Oficinalis Leaves extract on Acetaminophen-Induced Hepatotoxicity. JPMI. 2006;20(4):370-373.

53. Preethi KC, Kuttan G, Kuttan R. Antioxidant potential of an extract of Calendula officinalis flowers in vitro and in vivo. Pharmaceutical Biology. 2006;44(9):691-697.

54. Jain U, Purwal L, Shrivastav V, et al. Anthelmintic activity of aqueous extracts of some Saponin containing medicinal plants. Der Pharmacia Lettre. 2010;2(4):476-481.

55. Preethi KC, Kuttan G, Kuttan R. Anti-inflammatory activity of flower extract of Calendula officinalis Linn and its possible mechanism of action. Indian J Exp Biol. 2009;47(2):113-120.

56. Parente LML, Andrade MA, Brito AB, et al. Angiogenic activity of Calendula officinalis flowers L. in rats. Acta Cir Bras. 2011;26(1):19-26.

57. Robert A, Hadfield BS, Tracey C, et al. Pharmacological Activities of Calendula Officinalis. The Foot \& Ankle Journal. 2008;1(7):1-8.

58. Amirghofran Z, Azadbakht M, Karimi MH. Evaluation of the immunomodulatory effects of five herbal plants. J Ethnopharmacol. 2000;72(1-2):167-172.

59. Hussein MS, Osama S, Nour ET, et al. The Protective Effect Of Morus Alba and Calendula Officinalis plant extracts on Carbon Tetrachloride- Induced
Hepatotoxicity In Isolated Rat Hepatocytes. J Am Sci. 2010;6(10):762_773.

60. Roopashree TS, Dang R, Rani RH, et al. Antibacterial activity of antipsoriatic herbs: Cassia tora, Momordica charantia and Calendula officinalis. International Journal of Applied Research in Natural Products. 2008;1(3):20-28.

61. Dahake AP, Joshi VD, Joshi AB. Antimicrobial Screening of Different Extract of Anacardium occidentale Linn. Int $J$ ChemTech Res. 2009;1(4):856-858.

62. Safdar W, Majeed H, Naveed I, et al. Pharmacognostical study of the medicinal plant Calendula officinalis L. (family Compositae). Int J Cell Mol Biol. 2010;1:108-116.

63. Ostad SN, Esfahani HR, Taheri S et al. Effects of flavonoid fractions from calendula officinalis flowers in parent and tamoxifen resistant $t 47 \mathrm{~d}$ human breast cancer cells. Iranian Journal of Pharmaceutical Research. 2005;1(3):161-166

64. Beudot C, De Méo MP, Dauzonne D, et al. Evaluation of the mutagenicity and antimutagenicity of forty-two 3-substituted flavones in the Ames test. Mutat Res. 1998;417(2-3):141-153.

65. Herold A, Cremer L, Calugaru A, et al. Hydroalcoholic plant extracts with anti-inflammatory activity. Roum Arch Microbiol Immunol. 2003;62(12):117-129.

66. Pommier P, Gomez F, Sunyach M, et.al. Phase III randomized trial of Calendula officinalis compared with trolamine for the prevention of acute dermatitis during irradiation for breast cancer. J Clin Oncol. 2004;22(8):1447-1453.

67. Muley BP, Khadabadi SS, Banarase NB, et al. The Antioxidant Activity of the Leaves and Petals of Calendula officinalis Linn. Res J Pharm Tech. 2(1):173-175.

68. Preethi KC, Kuttan G, Kuttan R. Antioxidant potential of Calendula officinalis flowers in vitro and in vivo. Pharm Biol. 2006;44(9):691-697.

69. Minea R, Nemtanu M, Brasoveanu M, et al. Organoleptic properties invitro and in-vivo pharmacological activities of Calendula officinalis Linn. Proceeding of EPAC: Switzerland; 2004. p.2371-2373

70. Kalvatchev Z, Walder R, Garzaro D. Anti-HIV activity of extracts from Calendula officinalis flowers. Biomed Pharmacother. 1997;51(4):176180 